Research Article

\title{
The Main and Interactive Effects of Biological Maturity and Relative Age on Physical Performance in Elite Youth Soccer Players
}

\author{
James Parr $\mathbb{D}^{1},{ }^{1,2}$ Keith Winwood ${ }^{1}{ }^{1,3}$ Emma Hodson-Tole, ${ }^{1,3}$ Frederik J. A. Deconinck ${ }^{1 D},{ }^{4}$ \\ James P. Hill $(1),{ }^{5}$ Jan Willem Teunissen, ${ }^{4,6}$ and Sean P. Cumming ${ }^{7}$ \\ ${ }^{1}$ Department of Life Science, Manchester Metropolitan University, Manchester, UK \\ ${ }^{2}$ Manchester United Football Club, Manchester, UK \\ ${ }^{3}$ Musculoskeletal Sciences and Sports Medicine Research Centre, Department of Life Sciences, \\ Manchester Metropolitan University, Manchester, UK \\ ${ }^{4}$ Department of Movement \& Sports Sciences, Ghent University, Ghent, Belgium \\ ${ }^{5}$ Department of Electrical and Electronic Engineering, The University of Manchester, Manchester, UK \\ ${ }^{6}$ Department of Sports and Exercise Studies, HAN University of Applied Sciences, Nijmegen, Netherlands \\ ${ }^{7}$ Department for Health, University of Bath, Bath, UK
}

Correspondence should be addressed to James Parr; james.parr@manutd.co.uk

Received 25 January 2020; Revised 22 April 2020; Accepted 27 April 2020; Published 1 August 2020

Academic Editor: John Zhang

Copyright ( $\odot 2020$ James Parr et al. This is an open access article distributed under the Creative Commons Attribution License, which permits unrestricted use, distribution, and reproduction in any medium, provided the original work is properly cited.

The main and interactive effect of biological maturity and relative age upon physical performance in adolescent male soccer players was considered. Consistent with previous research, it was hypothesised that participants of greater maturity or born earlier in the selection year would perform better in terms of physical performance tests. This cross-sectional study consisted of 84 male participants aged between 11.3 and 16.2 years from a professional soccer academy in the English Premier League. Date of birth, height, weight, and parental height were collected. Sprint, change of direction, countermovement jump, and reactive strength index were considered for physical performance. Relative age was based on the birth quarter for the selection year. Maturity status was based upon the percentage of predicted adult height attained. Linear regression models highlighted that maturation was associated with performance on all but one of the physical performance tests, the reactive strength index. In contrast, relative age only served as a significant predictor of performance on the countermovement jump. This study indicated that physical performance (in the tests studied) seems to be related to the biological maturity status of a player but not their relative age. This finding is important because it suggests that early-maturing players perform better in the majority of physical performance tests, and the commonly held belief that relative age effect influences performance may be overstated.

\section{Introduction}

The identification and development of talented soccer players are primary objectives of professional soccer academies [1]. The aspects that define talent in soccer are multifaceted, meaning that the process of predicting future potential at early ages is challenging [2,3]. Previous research has attempted to identify factors that may predispose an individual towards becoming a successful soccer player such as anthropometric and physical (fitness) characteristics
$[4,5]$. Many of these attributes can, however, be confounded by the developmental differences that exist among players.

Biological maturation and relative age are two nonmodifiable attributes that have been shown to influence player selection, evaluation, and performance in youth soccer $[6,7]$. Biological maturation refers to the progress towards the mature adult state, varying among biological systems, and can be defined in terms of status, tempo, and timing [8], whereas "status" refers to the stage of maturation attained at a specific time-point (e.g., skeletal age or stage of pubic hair 
development); "tempo" describes the rate at which maturation advances in a specific system; and "timing" refers to the age at which specific maturational events, such as puberty, occur [9]. Of relevance, children of the same chronological age can demonstrate marked variation in biological maturation and maturity status with some individuals maturing well in advance or delay of their same age peers $[9,10]$. For example, within an under 9's soccer team, it is entirely possible to observe a child with a skeletal age (an established proxy of maturation) of seven years training and competing with a child who has a skeletal age of twelve years [10]. Individual differences in maturation are principally governed by a combination of heritable, i.e., genotypic and environmental factors, such as stress, nutrition, and social circumstances, as well as ethnicity [9]. The individual differences have been shown to directly and indirectly influence player performance and selection in youth soccer [11].

From the onset of puberty, boys who mature in advance of their peers possess a marked advantage in term of size and athleticism [12]. As the first individuals within their age group to experience the physical changes associated with puberty, these boys are typically taller, heavier, faster, stronger, and more powerful than their later maturing peers $[8,12,13]$. Consequently, these players are more likely to succeed in sports and activities that demand or prioritise these attributes. Selection biases towards early-maturing boys have been well established in soccer and are especially prevalent in professional soccer academies where there is an emphasis upon identifying and developing the most talented youth [14]. To survive in these programmes, talented yet late-maturing players must possess or develop exceptional technical, tactical, and/or psychological attributes, a phenomenon known as the "underdog effect." This hypothesises that younger and/or later maturing players must display these superior attributes $[8,15,16]$. While these skills may serve as an advantage in the long term, research suggests that very few of these individuals are retained within the academy system $[10,17]$.

Relative age refers to a child's chronological age within their age group and is determined by date of birth and the selection cutoff date. Children competing within a singleyear age group can vary by almost as much as 12 months in terms of their chronological age [18]. This relative age effect (RAE) describes a phenomenon whereby players that are born earlier in their selection year have a greater likelihood of representing and succeeding in their youth programmes. A bias has been reported highlighting the recruitment of individuals that are born earlier in their selection year [19], with findings suggesting that $36-50 \%$ of soccer players were born within the first three months of their selection year, and only between 4 and $17 \%$ were born within the last three months of their selection year $[1,20,21]$. The underlying causes of the RAE have often been attributed to physiological growth and maturation $[1,22]$. However, RAE is observed well in advance of maturity-associated selection biases and is also found in many achievement domains that do not require physical propensity, e.g., soccer referees [23], head coaches [24], and academia [25].

It is vital to note that relative age and biological maturation are not synonymous. Relative age and biological maturation are independent constructs that exist and operate independently of one another, and are governed by separate factors (i.e., birth and cutoff dates versus genetics/ environment). Within a single-year age group, there is also much greater scope for variation in biological maturity than relative age, whereas differences in relative age are limited to 12 months and differences in maturity can vary by up to six years [10]. As a consequence, it is entirely possible to be the eldest and least mature player within one's own age group, or vice versa. More recently, a study of relative age and maturation noted that Portuguese soccer players aged 11-13 years, born later in the year, were more likely to be advanced in skeletal maturity for their chronological age and sex than their peers born in the first quarter [26]. The independent nature of relative age and biological maturity can also be observed in the age at which their associated selection biases emerge and how they change with age, whereas RAE can be observed from six years of age and remain consistent through late childhood and adolescence, maturity-associated selection biases only emerge with the onset of puberty and tend to increase in magnitude with age and competitive level [9]. As RAE may exist well in advance of puberty, it is unlikely that these biases can be attributed to maturity-associated differences in athleticism (i.e., speed, power, and strength) which are not evident until approximately 11-12 years of age $[27,28]$, rather RAE is more likely to result from differences in playing experience, cognitive, emotional, behavioural, motor, and social development; all of which are more likely to follow age than maturity.

In light of the previous discussion, the purpose of the current study was to investigate the main and interactive effects of maturation and relative age upon fitness parameters: $5 \mathrm{~m}, 20 \mathrm{~m}$, change of direction, countermovement jump (CMJ), and reactive strength index (RSI) in elite youth soccer players. Specifically, it was predicted that maturation and relative age would be positively associated with physical performance as well as anthropometric measures. Furthermore, it was proposed that the performance advantages might be greatest in players who were both more mature and relatively old for their age groups.

\section{Methods}

2.1. Participants. The sample included 84 male participants aged between 11.3 and 16.2 years from a professional soccer academy in the English Premier League. Participants normally trained two-three times throughout the week and participated in competition once per week. Data collection occurred within the academy during the 2018-2019 season. Parents/legal guardians of the participants were informed of the aim of the study, research procedures, requirements, benefits, and risks. They provided written informed consent, and the participants also provided assent. Participants were advised that involvement was voluntary and that they could withdraw from the study at any point. Prior to the study commencing, ethical approval was obtained and granted from the Ethics Committee of the Faculty of Science and Engineering, at Manchester Metropolitan University. 
2.2. Anthropometry and Procedures. Stature (hereafter, "height") and weight ( $\mathrm{kg}$ ) were measured every two months throughout the competitive playing season (six measurements). Participants wore T-shirt and shorts, and footwear was removed during measurements. Height was measured using a fixed Harpenden stadiometer (Holtain Ltd., UK) to the nearest $0.10 \mathrm{~cm}$. Height was measured as the distance from the standing surface to the vertex of the head. Participants were instructed to stand in the normal erect posture with weight equally distributed between both feet. Body mass was measured by means of a weighing scale (Tanita ${ }^{\circledR}$, type BC-420 SMA, Japan) to the nearest $0.10 \mathrm{~kg}$. The height of the participant's biological parents were collected either by academy staff or self-reported by the parents, and the selfreported heights were adjusted for overestimation using sex specific equations [29].

2.3. Biological Maturity Status. Final adult height in youths can be predicted using the Khamis-Roche method [30]. This method uses an individual's chronological age, height, and weight, in addition to a calculation of midparental height of the biological parents (i.e., mean of the heights of biological parents) to predict final adult height. The median error in predicting adult height in boys using this method is $2.2 \mathrm{~cm}$ between 4.0 and 17.5 years of age. With predicted adult height as the reference, percentage of predicted final adult height attained at the time of observation was calculated [31], to provide an indication of biological maturity status [32]. This is the same index used to group players by maturation in recent studies of bio-banding $[15,33,34]$. It can be assumed that for children of the same chronological age, those closer to their predicted adult height may be assumed to be more advanced in maturation compared to those further away from their predicted adult height. For example, a boy that is $90 \%$ of his predicted adult height would be considered less mature than a boy of the same chronological age who has achieved $95 \%$ of his predicted adult height.

Estimated biological maturity status was expressed as a " $z$-score" relative to age and sex specific means and standard deviations for percentage of mature height attained at half-yearly intervals [35]. The $z$-scores were also used to classify each participant as either early, on time, or late in maturity, as used in previous studies [36-38]. Individuals that achieved a $z$-score of between -1 and +1 were classified as on time in maturity status, if individuals achieved a $z$-score greater than +1 , they were defined as early in maturity status, and if individuals achieved a $z$ score less than -1 , they were defined as late in maturity status.

2.4. Relative Age. The selection year for youth soccer in England spans 1st September-31st August. Relative age was established for each participant using their date of birth and the cutoff date of their selection year group (31st August). To allow comparison with the previous literature, relative age was classified into birth quartiles. These were defined as quarter one (oldest Q1): 1st September-30th November; quarter two (Q2): 1st December-28th (29th) February; quarter three (Q3): 1st March-31st May; and quarter four (youngest Q4): 1st June-31st August.

The measure of relative age was also expressed as a decimal, using the difference between a participant's birthdate and the selection cutoff date, divided by the number of days in a year [39]. Relative age was expressed as a value between 0.00 and 0.99 , with these values representing the youngest to oldest, respectively.

2.5. Physical Performance Tests. Following the collection of anthropometric variables, participants then undertook a dynamic 10-minute warmup with a qualified youth soccer coach. All participants were tested in their current age groups within the same week at the start of their training session. The sprinting and change of direction abilities of the participants were evaluated on $4 \mathrm{G}$ artificial turf. Participants were instructed to complete all tests in the following order: sprinting $(5 \mathrm{~m}$ and $20 \mathrm{~m})$, change of direction, countermovement jumps, and finally, drop jumps. A recovery period of $10 \mathrm{~min}$ was given between each test condition to avoid fatigue-induced effects [40].

2.6. Sprint Test. The sprinting abilities of participants were evaluated on $4 \mathrm{G}$ artificial turf by $20 \mathrm{~m}$ sprint times (standing start), with $5 \mathrm{~m}$ and $20 \mathrm{~m}$ split times. Gates were positioned at $0 \mathrm{~m}, 5 \mathrm{~m}$, and $20 \mathrm{~m}$, enabling a sprint time to be recorded between $0 \mathrm{~m}$ and $5 \mathrm{~m}, 5 \mathrm{~m}$ and $20 \mathrm{~m}$, and $0 \mathrm{~m}$ and $20 \mathrm{~m}$. Earlier research has highlighted reliability coefficients of variation were $<2.7 \%$ for youth team-sport players performing all out sprints over similar distances on similar surfaces [41]. All participants performed a familiarisation session to practice the tests and become accustomed with the procedures. For all sprints, participants adopted a two-point stance, with the front foot placed $0.30 \mathrm{~m}$ before $(-0.30 \mathrm{~m})$ the initial timing gate $(0 \mathrm{~m})$ to prevent early triggering, and were instructed to sprint as fast as possible in a straight line to the turning point, which was placed $5 \mathrm{~m}$ beyond the final gate $(25 \mathrm{~m})$. Time was recorded using photoelectric cells (Witty, Microgate, Italy). The sprints were performed four times, separated by at least three minutes of passive recovery between each attempt. Time for each distance was recorded to the nearest $0.01 \mathrm{~s}$, and the best time for each test was recorded for the statistical analysis as used previously in adolescent (elite) soccer players [42]. Figure 1 shows the layout of the gate positions for the sprint test.

2.7. Change of Direction: $180^{\circ}$ Test. Following a maximal sprint (protocol described previously), also described in the literature as a "flying start," participants were asked to sprint forward to a turning point $5 \mathrm{~m}$ beyond the $20 \mathrm{~m}$ timing gate $(25 \mathrm{~m})$ and pivot $180^{\circ}$, and the test was concluded when the participant rebroke the $20 \mathrm{~m}$ timing gate as shown in Figure 1. This test requires the participant to decelerate, change their body direction, by rotating $180^{\circ}$, 


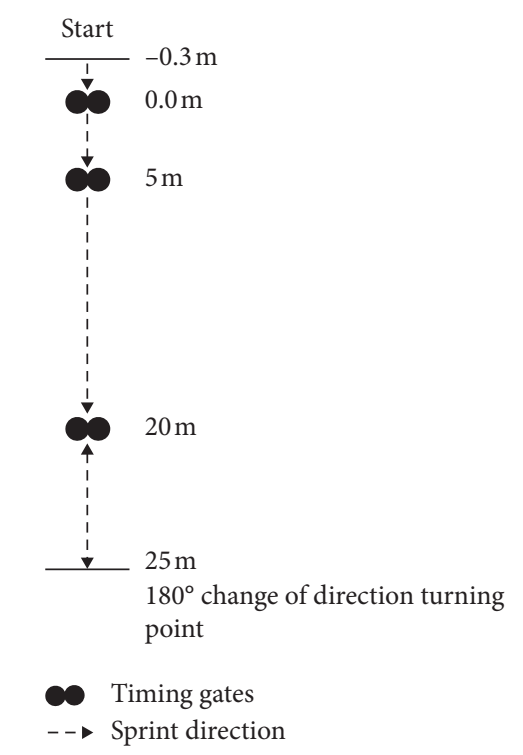

FIgURE 1: Schematic diagram of test layout.

and then accelerate. The test was repeated four times, with the turning foot alternated between their right and left foot, separated by at least three minutes of passive recovery between each test. Time was recorded using photoelectric cells (Witty, Microgate, Italy), to the nearest $0.01 \mathrm{~s}$. A practitioner was positioned at the turning point, and if the participant turned prematurely, with the wrong foot, or slipped, the trial was discarded and subsequently another trial was performed after a further three-minute rest. The fastest trial for the change of direction test was recorded for the statistical analysis as used previously in adolescent (elite) soccer players [43]. Figure 1 shows the layout of the gate positions for the change of direction test.

2.8. Countermovement Jump Test. The countermovement jump (CMJ) has previously been established to be a reliable measure of explosive power performance $[44,45]$. Following the maximal sprints, participants performed three jumps on a hard, flat surface between a portable photoelectric cell system (Optojump, Microgate, Bolzano, Italy), with 60 seconds of rest between trials. To isolate the lower limbs and reduce the influence of technique and arm swing [46], participants were asked to keep their arms akimbo during CMJs. Participants were instructed to begin the jump from an initial standing position with a downward movement to a self-selected squat depth [44], which is immediately followed by a concentric upward movement, resulting in a maximal vertical jump [47]. The final CMJ score was taken as the highest jump (cm) and used for statistical analysis as used previously in adolescent (elite) soccer players [43].

2.9. Reactive Strength Index. The reactive strength index (RSI) was determined using drop jump (DJ) tests, which involved the participants performing five separate jumps on a hard, flat surface between a portable photoelectric cell system (Optojump, Microgate, Bolzano, Italy). Participants performed DJs from a drop height of $0.30 \mathrm{~m}$ and were encouraged to use their hands during the jumps. Participants were asked to avoid stepping down or hopping from the box and avoid tucking in the air (i.e., legs remain straight and attempt to land in the same position as takeoff). Initially, participants stepped off the platform, dropped down to the floor, landed on both feet, and then immediately jumped up as quickly and as high as possible. The aim of the jumps was to minimise the contact time, while attempting to maximise flight time [48]. Between DJs, a rest period of 60 seconds was given to avoid any residual fatigue effects [49]. Every participant performed a practice jump for familiarisation. The dependent variables calculated for the jumps were contact time (CT) and flight time (FT). The RSI was calculated using equation (1) for each test. The best (highest) score was then selected as used previously in adolescent soccer players [50]:

$$
\mathrm{RSI}=\frac{\mathrm{FT}}{\mathrm{CT}} \text {. }
$$

An overall timeline for all test conditions and their duration are shown in Figure 2.

2.10. Statistical Analyses. Descriptive statistics were calculated for the variables of interest and were reported via mean and standard deviation (SD). Pearson product moment correlations were calculated for the following variables: estimated maturity status, percentage of predicted adult height, relative age, height $(\mathrm{cm})$, weight $(\mathrm{kg})$, chronological age (years), $5 \mathrm{~m} \mathrm{(s),} 20 \mathrm{~m}$ (s), change of direction (s), CMJ $(\mathrm{cm})$, and RSI. Hierarchical regression analysis was used to evaluate the main and interactive effects of relative age (decimal) and maturation ( $z$-score) upon the performance parameters. Step 1 of the hierarchical regression analysis considered just the main effects of biological maturity and relative age, and step 2 then also considered the interaction effect between these two variables. The process of centring (subtracting the current score from group average) was used to create the interaction score (multiplying the centred scores) between biological maturity and relative age to reduce potential issues associated with collinearity. SPSS (IBM SPSS 24) was used for all analyses.

\section{Results}

3.1. Descriptive Statistics. The descriptive statistics for estimated biological maturity, predicted adult height, relative age, height, weight, and performance parameters, including $5 \mathrm{~m}, 20 \mathrm{~m}$, change of direction, CMJ, and RSI are presented in Table 1. The mean value for relative age was 0.67 years (i.e., Q2) across all age groups and did not appear to increase or decrease with age. Among the total sample of 84 participants, 43 participants (51\%) were born in Q1, 22 participants (26\%) were born in Q2, 11 participants (13\%) were born in birth Q3, and 8 participants (10\%) were born in Q4. A chi-squared test $\left(\chi^{2}=35.9, p<0.01\right)$ indicates that there was an uneven distribution among the quartiles. The mean maturity $z$-score was either approximately zero or had a positive value in the U13 to U16 age groups. Only in the U12 


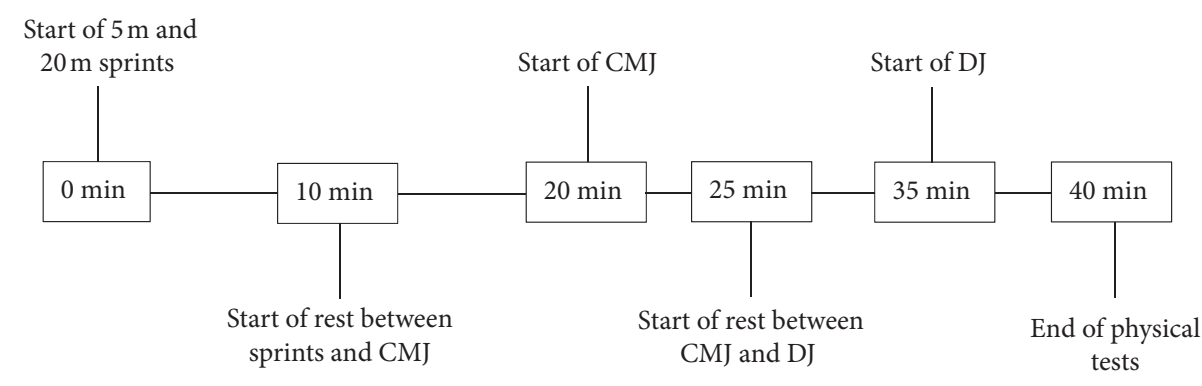

FIGURE 2: Breakdown of timeframes of test conditions during the study.

TABLE 1: Descriptive statistics of participants per age group.

\begin{tabular}{|c|c|c|c|c|c|c|c|c|c|c|}
\hline \multirow{2}{*}{ Variables } & \multicolumn{2}{|c|}{$\mathrm{U} 12(n=24)$} & \multicolumn{2}{|c|}{$\mathrm{U} 13(n=19)$} & \multicolumn{2}{|c|}{$\mathrm{U} 14(n=21)$} & \multicolumn{2}{|c|}{$\mathrm{U} 15(n=8)$} & \multicolumn{2}{|c|}{$\mathrm{U} 16(n=12)$} \\
\hline & $\bar{x}$ & $\mathrm{SD}$ & $\bar{x}$ & $\mathrm{SD}$ & $\bar{x}$ & $\mathrm{SD}$ & $\bar{x}$ & $\mathrm{SD}$ & $\bar{x}$ & $\mathrm{SD}$ \\
\hline Chronological age & 11.75 & 0.29 & 12.73 & 0.34 & 13.63 & 0.25 & 14.68 & 0.38 & 15.67 & 0.38 \\
\hline Height $(\mathrm{cm})$ & 150.20 & 6.40 & 160.70 & 8.69 & 162.20 & 8.30 & 175.20 & 6.70 & 176.40 & 6.74 \\
\hline Weight $(\mathrm{kg})$ & 39.2 & 4.30 & 45.90 & 8.10 & 48.10 & 6.20 & 63.10 & 8.30 & 63.50 & 7.20 \\
\hline Predicted adult height $(\mathrm{cm})$ & 182.4 & 5.30 & 185.7 & 6.3 & 180.5 & 7.1 & 183.5 & 2.7 & 182.2 & 4.9 \\
\hline Relative age & 0.68 & 0.28 & 0.67 & 0.31 & 0.69 & 0.25 & 0.76 & 0.23 & 0.58 & 0.38 \\
\hline Maturity $z$-score & -0.07 & 0.80 & 0.33 & 0.82 & 0.01 & 0.46 & 0.42 & 0.51 & 0.20 & 0.50 \\
\hline $5 \mathrm{~m}$ sprint $(\mathrm{s})$ & 1.15 & 0.05 & 1.12 & 0.06 & 1.08 & 0.06 & 1.08 & 0.08 & 1.06 & 0.05 \\
\hline $20 \mathrm{~m}$ sprint $(\mathrm{s})$ & 3.51 & 0.13 & 3.28 & 0.37 & 3.25 & 0.12 & 3.12 & 0.14 & 3.14 & 0.21 \\
\hline Change of direction (s) & 2.58 & 0.14 & 2.36 & 0.07 & 2.27 & 0.09 & 2.24 & 0.06 & 2.21 & 0.13 \\
\hline $\mathrm{CMJ}(\mathrm{cm})$ & 24.97 & 3.56 & 27.10 & 4.68 & 31.60 & 4.50 & 36.60 & 5.70 & 32.90 & 4.50 \\
\hline RSI & 2.00 & 0.40 & 1.73 & 0.27 & 2.07 & 0.31 & 2.43 & 0.27 & 2.49 & 0.37 \\
\hline
\end{tabular}

Note. $\bar{x}$ is mean, and SD is standard deviation. Relative age was calculated as the difference between the participant's birthdate and the cutoff date (31st August). This was then divided by the number of days within the year (365 days).

age group, the maturity $z$-score was below zero. Individuals that achieved a $z$-score of between -1 and +1 were classified as on time in maturity status, if individuals achieved $z$-score greater than +1 , they were defined as early in maturity status, and if individuals achieved a $z$-score less than -1 , they were defined as late in maturity status.

In terms of biological maturation, the majority of the participants $(89 \%)$ fell within \pm 1.0 standard deviation of the reference mean for their sex and age, whereas nine of the participants (11\%) could be categorized as being advanced in maturation (i.e., $>1.0$ standard deviation above mean reference value for age and sex); no participants were considered late maturing (i.e., <1.0 standard deviation below mean reference value for age and sex).

3.2. Correlational Analyses. The results of the correlational analyses are summarised in Table 2. Of note, maturation was negatively correlated with $5 \mathrm{~m}, 20 \mathrm{~m}$, and change of direction test, indicating that players advanced in maturity status ran quicker over the set distances and changed direction more quickly. Maturity was positively associated with performance on the CMJ test, indicating that players advanced in maturation demonstrated greater prowess for jumping higher. Relative age was negatively associated with performance on the sprint test, but only at $20 \mathrm{~m}$, and positively associated with performance on the CMJ test.
Maturity correlations were statistically significant at $p<0.01$, and relative age was statistically significant at $p<0.05$.

3.3. Regression Analysis. The results for each hierarchical regression model for the different performance variables are presented in Tables 3-7.

The final regression model for $5 \mathrm{~m}$ sprint times achieved statistical significance, $F(3,79)=4.57, p<0.01$ (Table 3$)$. In the final model, maturation served as a statistically significant negative predictor of time in both the main and interactive models. Relative age and the interaction between relative age and maturation did not predict any of the variance in sprint performance over $5 \mathrm{~m}$.

The results for the regression model predicting variance in performance in the $20 \mathrm{~m}$ sprint task are presented in Table 4. The final model was statistically significant, $F$ (3, $79)=4.62, p<0.01$. As with the $5 \mathrm{~m}$ sprint test, a main effect was observed for maturity but not relative age or the interaction term, although maturity status only had an effect in the main model. More specifically, maturation was inversely associated with $20 \mathrm{~m}$ sprint time.

The regression model for change of direction times was also statistically significant, $F(3,80)=3.83, p<0.05(\mathrm{Ta}-$ ble 5). Statistically significant main effects were observed for maturity in the main model; however, relative age and the 
TABLE 2: $R$ values for correlational analyses between various anthropometric, maturity, and fitness parameters.

\begin{tabular}{|c|c|c|c|c|c|c|c|c|c|c|c|c|}
\hline Variables & $\mathrm{CA}$ & $\mathrm{BA}$ & Maturity " $z$ " & RA & Height & Weight & PAH & $5 \mathrm{~m}$ & $20 \mathrm{~m}$ & COD & $\mathrm{CMJ}$ & RSI \\
\hline $\mathrm{CA}$ & - & & & & & & & & & & & \\
\hline BA & $0.92^{* *}$ & - & & & & & & & & & & \\
\hline Maturity " $z$ " & $0.19^{*}$ & $0.52^{* *}$ & - & & & & & & & & & \\
\hline RA & 0.11 & 0.13 & -0.04 & - & & & & & & & & \\
\hline Height & $0.78^{* *}$ & $0.90^{* *}$ & $0.59^{* *}$ & 0.14 & - & & & & & & & \\
\hline Weight & $0.81^{* *}$ & $0.88^{* *}$ & $0.46^{* *}$ & 0.17 & $0.90^{* *}$ & - & & & & & & \\
\hline $\mathrm{PAH}$ & -0.03 & 0.10 & $0.36^{* *}$ & 0.06 & $0.53^{* *}$ & $0.35^{* *}$ & - & & & & & \\
\hline $5 \mathrm{~m}$ sprint & $-0.65^{* *}$ & $-0.68^{* *}$ & $-0.35^{* *}$ & -0.08 & $-0.61^{* *}$ & $-0.58^{* *}$ & -0.08 & - & & & & \\
\hline $20 \mathrm{~m}$ sprint & $-0.61^{* *}$ & $-0.64^{* *}$ & $-0.32^{* *}$ & $-0.19^{*}$ & $-0.60^{* *}$ & $-0.58^{* *}$ & -0.10 & $0.66^{* *}$ & - & & & \\
\hline COD & $-0.77^{* *}$ & $-0.75^{* *}$ & $-0.33^{* *}$ & -0.08 & $-0.64^{* *}$ & $-0.60^{* *}$ & 0.02 & $0.66^{* *}$ & $0.61^{* *}$ & - & & \\
\hline $\mathrm{CMJ}$ & $0.70^{* *}$ & $0.71^{* *}$ & $0.32^{* *}$ & $0.23^{*}$ & $0.62^{* *}$ & $0.67^{* *}$ & 0.01 & $-0.62^{* *}$ & $-0.65^{* *}$ & $-0.60^{* *}$ & - & \\
\hline RSI & $0.58^{* *}$ & $0.47^{* *}$ & -0.06 & 0.05 & $0.31^{* *}$ & $0.43^{* *}$ & $-0.23^{*}$ & $-0.36^{* *}$ & $-0.37^{* *}$ & $-0.42^{* *}$ & $0.46^{* *}$ & - \\
\hline
\end{tabular}

${ }^{*}$ Correlation is significant at the 0.05 level (1-tailed). ${ }^{* *}$ Correlation is significant at the 0.01 level (1-tailed). CA: chronological age; BA: biological age; RA: relative age; PAH: predicted adult height; COD: change of direction.

TABLE 3: Summary of hierarchical regression analysis for variables predicting $5 \mathrm{~m}(\mathrm{~s})$ sprint time.

\begin{tabular}{lccccccc}
\hline Variable & \multicolumn{3}{c}{ Model 1 } & \multicolumn{3}{c}{ Model 2 } \\
& B & SE B & $\beta$ & B & SE B & $\beta$ \\
\hline Maturity status & -0.03 & 0.01 & $-0.35^{* *}$ & -0.07 & 0.03 & $-0.74^{* *}$ \\
(MS) & & & -0.10 & -0.01 & 0.02 & -0.05 \\
Relative age (RA) & -0.02 & 0.02 & -0.04 & 0.30 & 0.42 \\
Interaction & & & & 0.15 & & \\
MS $\times$ RA & & & & 0.57 & & \\
$R^{2}$ & 0.13 & & & 4.57 \\
$F$ for change in $R^{2}$ & 5.93 & & &
\end{tabular}

${ }^{*} p<0.05 .{ }^{* *} p<0.01$.

TABLE 4: Summary of hierarchical regression analysis for variables predicting $20 \mathrm{~m}$ (s) sprint time.

\begin{tabular}{lrccccc}
\hline Variable & \multicolumn{3}{c}{ Model 1 } & \multicolumn{3}{c}{ Model 2 } \\
& B & SE B & $\beta$ & B & SE B & $\beta$ \\
\hline $\begin{array}{l}\text { Maturity status } \\
\text { (MS) }\end{array}$ & -0.13 & 0.39 & $-0.33^{* *}$ & -0.17 & 0.12 & $-0.47^{* *}$ \\
Relative age (RA) & -0.17 & 0.86 & -0.21 & -0.16 & 0.09 & -0.19 \\
Interaction & & & & 0.05 & 0.11 & 0.14 \\
MS $\times$ RA & & & & 0.15 & & \\
$R^{2}$ & 0.15 & & & 4.62 & & \\
$F$ for change in $R^{2}$ & 6.90 & & & & & \\
${ }^{*} p<0.05{ }^{* *} p<0.01$. & & & & &
\end{tabular}

interaction term did not serve as significant predictors in the models. Maturation was inversely associated with change of direction times, indicating superior performance in more mature and relatively older players.

The regression model for CMJ was also statistically significant, $F(3,77)=5.32, p<0.05$ (Table 6). Again maturity was shown to be significant for CMJ in the main model. Unlike for the previous tests, the main and interaction effects revealed a statistically significant effect for relative age. The interaction term for maturity and relative age was shown to be nonsignificant. Specifically, maturation was positively associated with CMJ heights indicating an athletic advantage associated with advanced maturation.
TABLE 5: Summary of hierarchical regression analysis for variables predicting change of direction (s) ability.

\begin{tabular}{lcccccc}
\hline Variable & \multicolumn{3}{c}{ Model 1 } & \multicolumn{3}{c}{ Model 2 } \\
& B & SE B & $\beta$ & B & SE B & $\beta$ \\
\hline $\begin{array}{l}\text { Maturity status } \\
\text { MS) }\end{array}$ & -0.08 & 0.02 & $-0.34^{* *}$ & -0.14 & 0.07 & $-0.63^{* *}$ \\
Relative age (RA) & -0.05 & 0.05 & -0.09 & -0.27 & 0.06 & -0.05 \\
Interaction & & & & 0.07 & 0.07 & 0.32 \\
MS $\times$ RA & & & & 0.13 & & \\
$R^{2}$ & 0.12 & & & 3.83 & & \\
$F$ for change in $R^{2}$ & 5.29 & & & &
\end{tabular}

${ }^{*} p<0.05 .{ }^{* *} p<0.01$.

TABLE 6: Summary of hierarchical regression analysis for variables predicting $\mathrm{CMJ}(\mathrm{cm})$ ability.

\begin{tabular}{lcccccc}
\hline \multirow{2}{*}{ Variable } & \multicolumn{3}{c}{ Model 1 } & \multicolumn{3}{c}{ Model 2 } \\
& $\mathrm{B}$ & SE B & $\beta$ & $\mathrm{B}$ & SE B & $\beta$ \\
\hline Maturity status (MS) & 2.80 & 0.86 & $0.33^{* *}$ & 3.82 & 2.58 & $0.45^{* *}$ \\
Relative age (RA) & 4.65 & 1.94 & $0.24^{* *}$ & 4.34 & 2.09 & $0.23^{*}$ \\
Interaction MS $\times$ RA & & & & -1.06 & 2.53 & -0.13 \\
$R^{2}$ & 0.16 & & 0.17 & & \\
$F$ for change in $R^{2}$ & 7.97 & & 5.32 & & \\
${ }^{*} p<0.05 .{ }^{* *} p<0.01$. & & & & &
\end{tabular}

Equally, relative age showed a positive association; participants born earlier in the selection year showed improved performance.

In contrast, the regression model for RSI did not achieve statistical significance, $F(3,71)=0.32, p>0.05$ (Table 7). Inspection of the main and interaction effects revealed no statistically significant association between predictor variables and RSI performance.

\section{Discussion}

The purpose of this study was to investigate the main and interactive effects of maturity status and relative age upon physical performance in a series of fitness tests amongst a sample of 84 professional academy soccer players. It was 
TABLE 7: Summary of hierarchical regression analysis for variables predicting RSI ability.

\begin{tabular}{lcccccc}
\hline \multirow{2}{*}{ Variable } & \multicolumn{3}{c}{ Model 1 } & \multicolumn{3}{c}{ Model 2 } \\
& B & SE B & $\beta$ & B & SE B & $\beta$ \\
\hline Maturity status (MS) & -0.04 & 0.08 & -0.06 & 0.13 & 0.25 & 0.18 \\
Relative age (RA) & 0.08 & 0.18 & 0.05 & 0.03 & 0.19 & 0.02 \\
Interaction MS $\times$ RA & & & & -0.18 & 0.25 & -0.26 \\
$R^{2}$ & 0.01 & & & 0.01 & & \\
$F$ for change in $R^{2}$ & 0.22 & & 0.32 & & \\
${ }^{*} p<0.05 .{ }^{* *} p<0.01$. & & & &
\end{tabular}

found that the interactive effect of maturity status and relative age was small, therefore showing that these are two independent constructs that must be treated separately when considering the development of male adolescent soccer players. Maturity status was shown to have a much greater influence on performance which should be accounted for when considering soccer players of the same chronological age.

Consistent with previous literature $[7,19,25]$, participants in the current study tended to be relatively older for their age group and average-to-advanced in biological maturity. The majority of participants (77\%) were born in the first half of their competitive year, with more than half of the total participants being born in the first birth quarter (51\%). Collectively, these values suggested the presence of a strong RAE that is present from late childhood and maintained throughout the academy structure. This observation is of concern as previous research suggests that late-maturing and/or younger players, though under-represented in youth soccer, are psychologically and technically more proficient than their peers $[39,51,52]$. The cause of this trend could be attributed to a need for less physically developed players to exemplify better technical and/or psychological ability in order to compete with early-maturing individuals. Alternatively, this could be a feature of selection where coaches will only prefer a less physically developed player if their technical and/or psychological skills are already much advanced in comparison to physically developed individuals.

The results of the current investigation are consistent with previous research within youth soccer which has used skeletal age as an indicator of maturity status, whereby advanced maturity status appeared to act as a positive predictor of persistence, selection, and retention $[8,12,53]$. Moreover, further research is needed in order to understand the nature of the bias and redress the situation that is present where talented but late-maturing players are being omitted from an academy system.

The results pertaining to the associations between biological maturity, relative age, and physical fitness are of particular interest (Tables 3-7). First, it is important to note that biological maturity and relative age were found to be unrelated. This supports the contention that biological maturity and relative age are constructs or processes that exist and operate independently of one another. Accordingly, RAE cannot be attributed to the functional advantages that are associated with advanced biological maturation, which typically emerges around the onset of puberty [12]. It should be noted, however, that within this sample, relative age was found to present a positive, yet weak, and nonsignificant association with height and weight. Thus, RAE may be more likely to be associated with individual differences in growth than maturation, per se. To better understand and counter the selection biases associated with relative age and biological maturation, it is important that researchers and practitioners recognise the differences between these constructs. As noted, the selection biases associated with biological maturity and relative age emerge at different ages and it is likely that the mechanisms underpinning these biases are also different. Therefore, strategies designed to address and minimise the selection-induced RAE (e.g., average team age competitions, implementation of quotas for even representation of children of all birth months, and age-ordered shirts) should focus on developmental attributes more closely associated with age rather than maturity (i.e., cognition, motor skills, and experience) and may need to be introduced from an earlier age and at the grass roots level. In contrast, strategies designed to address maturity selection biases (e.g., bio-banding) are better reserved for late childhood and early puberty, when maturityassociated differences in size and function become much more salient.

Contrary to expectations, relative age was found to be largely unrelated to the measure of physical fitness. That is, relatively older players did not appear to perform any better on tests of speed, strength, and power than their younger peers. With respect to the correlational analyses (Table 2), relative age was only significantly associated with performance on the $20 \mathrm{~m}$ sprint and the CMJ tests. Older players did perform better on these tests; however, the magnitude of the associations was weak to moderate. In contrast, maturation was associated with performance on all but one of the physical performance tests (RSI). Specifically, advanced maturation was associated with superior performance on tests of speed, change of direction, and CMJ. The magnitude of these associations was moderate and notably greater than those equivalent values observed for relative age. The results of the regression models provided further insight into the main and interactive effects of biological maturation and relative age upon performance on the physical tests. With the exception of the RSI test, all of the regression models were statistically significant. Maturation served as a statistically significant and positive predictor of performance in the $5 \mathrm{~m}$ and $20 \mathrm{~m}$ sprint tests, the change of direction test, and the CMJ test. In contrast, relative age only served as a significant predictor of performance on the CMJ. The interaction between biological maturation and relative age failed to serve as a significant predictor of performance on all of the fitness tests. Collectively, these results suggest that physical fitness in academy soccer players is more likely to be associated with variance in biological maturity rather than relative age. Such selection biases are more likely to result from age-related differences in other developmental attributes such as experience, motor skills, and cognitive and/or social skills [39]. The results of the current study also suggest that maturation and relative age do not interact to influence 
fitness within this cohort. That is, being relatively older or younger within one's age group appears to have little to no bearing on the fitness performances of players who are advanced or delayed in maturation.

The fact that RAE has an influence on CMJ is interesting. The countermovement jump is a lower limb power test which is a fundamental variable for performance in soccer, and therefore, the fact that this is influenced by RAE is of significant importance to the conclusion of this study. While other tests (e.g., speed, change of direction, and transfer of power (RSI)) were not affected by RAE, it cannot be completely discounted from discussions around performance within a soccer setting.

The results of this investigation have important practical implications for those involved in the identification and development of talented young male soccer players. From a talent identification perspective, it is important to note that players who are advanced in biological maturity for their age group will possess a significant advantage in terms of their physical fitness [54]. As a consequence, players who mature early may perform better during competitions and on tests of physical aptitude. Technically gifted yet later maturing players are physically disadvantaged and may struggle to compete when matched against physically more able peers. As a consequence, late-maturing players may be more likely to be overlooked or excluded from the academy system. From a developmental perspective, players who mature in advance of their peers may also be more likely to play to their physical strengths, neglecting their technical, tactical, and psychological skills [15]. While such a strategy may bring immediate success, its value in the long term is limited as maturity-associated differences in size and function are typically attenuated, and in some cases, it is reversed, in early adulthood. Through being side-lined or as a result of the magnitude of these differences, late-maturing players may have less opportunity to apply, demonstrate, or develop these skills, regardless of ability [55]. To address the aforementioned concerns, it is important that coaches and practitioners both recognise and become aware of individual differences in players' maturation. Individual differences in biological maturity status have been shown to directly and indirectly influence player performance and selection in youth football [11]. The results of the current study highlight the significant role of individual differences in biological maturity status in the physical performance capacity of adolescent soccer players. Recently, the English Premier League has trialled the practice of bio-banding whereby players within a specific chronological age group are banded by estimated maturity status in an effort to balance maturityassociated differences in size and function. In order to individualise the selection and training processes, the Royal Belgian Football Association distinguishes players based on their developmental age, rather than birth year [56, 57]. However, there can be advantages for late developers mixing with players of different biological ages. The late developers will face challenges and will need to adapt technically, tactically, and mentally; these challenges will be missed if they only practice with players of a similar developmental age [58].
There are several limitations of the current study that should be highlighted. First of all, the results of the present study are restricted to one single soccer academy and therefore may not be generalizable and relative to other academy settings and game programmes. Secondly, parental heights, which were used for the estimation of biological maturity status, were largely self-reported, and reference values used to estimate the $z$-scores were based only on European (Caucasian) ancestry, yet this group includes nonCaucasian participants. A further limitation is that the study only considered tests of physical performance; results for the influence of biological maturity status and RAE may be different for tests, for example, social, psychological, technical, and tactical factors. For example, Cumming et al. [39] showed that maturity status had a strong correlation with psychological factors such as self-regulated learning.

It should also be noted that the participants in this present study in terms of both of biological maturity status and RAE were not evenly distributed. Less than $10 \%$ of participants were born in Q4, whereas $51 \%$ were born in Q1. A more balanced distribution may have shown stronger correlations between RAE and physical performance tests, and it may be possible that there is preferential deselection of the weakest Q4 participants. Only nine of the participants were early maturers, and there were no late maturers in the selection sample; hence, some of the correlations between maturity status and physical performance tests may be diluted as the majority of participants fell within \pm 1.0 standard deviations of the average for their age. Note that the current study included nine goalkeepers (11\%) who may be expected to experience a different performance profile to that of an outfield player, and a larger study in the future may be able to account for this. However, Table 8 compares the means between both the outfielders and goalkeepers in the present study. Goalkeepers were older, taller, and weighed more with a small-to-medium effect size $(p>0.05$, Cohen's $d=0.35$, $d=0.40$, and $d=0.51$, respectively) than outfield players. Moreover, outfield players outperformed the goalkeepers in all of the physical performance tests with a small-to-medium effect size: $5 \mathrm{~m}, p<0.05, d=0.42 ; 20 \mathrm{~m}, p>0.05, d=0.38$; change of direction, $p>0.05, d=0.35$; CMJ, $p>0.05$, $d=0.07$; and RSI, $p>0.05, d=0.24$.

This study has found that physical performance in the tests studied was seen to be related to the biological maturity status of a player. Relative age was only seen to have an influence on one performance test $(\mathrm{CMJ})$, which is strongly related to this sport. The influence of RAE is much less significant than biological maturity status but may be an important secondary factor in some instances. Coaches and practitioners should be aware of this and can use this information to be better informed of the relative performance of the players within their academy. Further longitudinal research is required to assess the role of physical performance in relation to player retention and deselection, including the impact of nonphysical parameters in this process. Other studies that may advance this work could be to investigate the influence of differences between academy settings, for example, the impact of a January-December rather than September-August selection year, may have on 
TABLE 8: Descriptive variables and comparisons of positional means \pm SD in physical performance tests between outfielders and goalkeepers.

\begin{tabular}{lcc}
\hline & Outfielders & Goalkeepers \\
\hline CA (years) & $13.24 \pm 1.36$ & $13.73 \pm 1.52$ \\
Height $(\mathrm{cm})$ & $161.1 \pm 11.7$ & $165.9 \pm 12.1$ \\
Weight $(\mathrm{cm})$ & $48.0 \pm 10.9$ & $53.5 \pm 10.6$ \\
$5 \mathrm{~m}(\mathrm{~s})$ & $1.11 \pm 0.10^{*}$ & $1.15 \pm 0.09$ \\
$20 \mathrm{~m}(\mathrm{~s})$ & $3.33 \pm 0.25$ & 3.430 .27 \\
COD $(\mathrm{s})$ & $2.34 \pm 0.17$ & $2.40 \pm 0.17$ \\
CMJ $(\mathrm{cm})$ & $29.4 \pm 5.64$ & $29.0 \pm 6.02$ \\
RSI & $2.10 \pm 0.37$ & $2.02 \pm 0.30$ \\
\hline
\end{tabular}

Note. CA: chronological age; COD: change of direction; CMJ: countermovement jump; RSI: reactive strength index. ${ }^{*} p<0.05$, difference between outfielders and goalkeepers.

the relationship between RAE and physical performance tests. A further major advance would be made by making a similar assessment of biological maturation and relative age on actual match performance rather than training data, as match performance is arguably more important and has a different set of motivational and environmental influences.

\section{Data Availability}

The data used to support the findings of this study are available from the corresponding author.

\section{Conflicts of Interest}

The authors declare that they have no conflicts of interest.

\section{References}

[1] C. Carling, F. Le Gall, T. Reilly, and A. M. Williams, "Do anthropometric and fitness characteristics vary according to birth date distribution in elite youth academy soccer players?," Scandinavian Journal of Medicine \& Science in Sports, vol. 19, no. 1, pp. 3-9, 2009.

[2] T. Reilly, A. M. Williams, A. Nevill, and A. Franks, "A multidisciplinary approach to talent identification in soccer," Journal of Sports Sciences, vol. 18, no. 9, pp. 695-702, 2000.

[3] R. Vaeyens, A. Güllich, C. R. Warr, and R. Philippaerts, "Talent identification and promotion programmes of olympic athletes," Journal of Sports Sciences, vol. 27, no. 13, pp. 1367-1380, 2009.

[4] S. Gil, F. Ruiz, A. Irazusta, J. Gil, and J. Irazusta, "Selection of young soccer players in terms of anthropometric and physiological factors," The Journal of Sports Medicine and Physical Fitness, vol. 47, no. 1, pp. 25-32, 2007.

[5] T. Reilly, J. Bangsbo, and A. Franks, "Anthropometric and physiological predispositions for elite soccer," Journal of Sports Sciences, vol. 18, no. 9, pp. 669-683, 2000.

[6] C. Meylan, J. Cronin, J. Oliver, and M. Hughes, "Talent identification in soccer: the role of maturity status on physical, physiological and technical characteristics," International Journal of Sports Science \& Coaching, vol. 5, no. 4, pp. 571-592, 2010.

[7] M. Sierra-Díaz, S. González-Víllora, J. Pastor-Vicedo, and J. Serra-Olivares, "Soccer and relative age effect: a walk among elite players and young players," Sports, vol. 5, no. 1, p. 5, 2017.
[8] R. M. Malina, A. D. Rogol, S. P. Cumming, M. J. Coelho E Silva, and A. J. Figueiredo, "Biological maturation of youth athletes: assessment and implications," British Journal of Sports Medicine, vol. 49, no. 13, pp. 852-859, 2015.

[9] R. M. Malina, O. Bar-Or, and C. Bouchard, Growth, Maturation, and Physical Activity, Human Kinetics, Champaign, IL, USA, 2nd edition, 2004.

[10] A. Johnson, "Monitoring the immature athlete," Aspetar Sports Medicine Journal, vol. 4, pp. 114-118, 2015.

[11] S. P. Cumming, R. S. Lloyd, J. L. Oliver, J. C. Eisenmann, and R. M. Malina, "Bio-banding in sport: applications to competition, talent identification, and strength and conditioning of youth athletes," Strength and Conditioning Journal, vol. 39, no. 2, pp. 34-47, 2017.

[12] A. Johnson, A. Farooq, and R. Whiteley, "Skeletal maturation status is more strongly associated with academy selection than birth quarter," Science and Medicine in Football, vol. 1, no. 2, pp. 157-163, 2017.

[13] A. J. Figueiredo, C. E. Gonçalves, M. J. Coelho E Silva, and R. M. Malina, "Characteristics of youth soccer players who drop out, persist or move up," Journal of Sports Sciences, vol. 27, no. 9, pp. 883-891, 2009.

[14] R. M. Malina, "Growth and maturity status of young soccer players," in Science and Soccer, T. Reilly and A. M. Williams, Eds., Routledge, London, UK, 2003.

[15] S. P. Cumming, D. J. Brown, S. Mitchell et al., "Premier league academy soccer players' experiences of competing in a tournament bio-banded for biological maturation," Journal of Sports Sciences, vol. 36, no. 7, pp. 757-765, 2018.

[16] L. Fumarco, B. G. Gibbs, J. A. Jarvis, and G. Rossi, "The relative age effect reversal among the National Hockey League elite," PLoS One, vol. 12, no. 8, Article ID e0182827, 2017.

[17] M. Hill, S. Scott, R. M. Malina, D. Mcgee, and S. P. Cumming, "Relative age and maturation selection biases in academy football," Journal of Sports Sciences, pp. 1-9, 2019.

[18] N. Wattie, J. Schorer, and J. Baker, "The relative age effect in sport: a developmental systems model," Sports Medicine, vol. 45, no. 1, pp. 83-94, 2015.

[19] W. F. Helsen, J. Van Winckel, and A. M. Williams, "The relative age effect in youth soccer across Europe," Journal of Sports Sciences, vol. 23, no. 6, pp. 629-636, 2005.

[20] C. Augste and M. Lames, "The relative age effect and success in German elite U-17 soccer teams," Journal of Sports Sciences, vol. 29, no. 9, pp. 983-987, 2011.

[21] J. H. Williams, "Relative age effect in youth soccer: analysis of the FIFA U17 world cup competition," Scandinavian Journal of Medicine and Science in Sports, vol. 20, no. 3, pp. 502-508, 2010.

[22] S. Cobley, J. Baker, N. Wattie, and J. Mckenna, "Annual agegrouping and athlete development: a meta-analytical review of relative age effects in sport," Sports Medicine, vol. 39, no. 3, pp. 235-256, 2009.

[23] N. Delorme, R. Radel, and M. Raspaud, "Relative age effect and soccer refereeing: a "strategic adaptation" of relatively younger children?," European Journal of Sport Science, vol. 13, no. 4, pp. 400-406, 2013.

[24] S. P. Cobley, J. Schorer, and J. Baker, "Relative age effects in professional German soccer: a historical analysis," Journal of Sports Sciences, vol. 26, no. 14, pp. 1531-1538, 2008.

[25] J. Musch and S. Grondin, "Unequal competition as an impediment to personal development: a review of the relative age effect in sport," Developmental Review, vol. 21, no. 2, pp. 147-167, 2001.

[26] A. J. Figueiredo, M. J. Coelho-E-silva, S. P. Cumming, and R. M. Malina, "Relative age effect: characteristics of youth 
soccer players by birth quarter and subsequent playing status," Journal of Sports Sciences, vol. 37, no. 6, pp. 677-684, 2019.

[27] R. M. Malina, "Growth and maturity of young soccer (football) players," in Science and Soccer, T. Reilly and A. M. Williams, Eds., Routledge, London, UK, 2003.

[28] L. B. Sherar, A. D. G. Baxter-Jones, R. A. Faulkner, and K. W. Russell, "Do physical maturity and birth date predict talent in male youth ice hockey players?," Journal of Sports Sciences, vol. 25, no. 8, pp. 879-886, 2007.

[29] L. H. Epstein, A. M. Valoski, M. A. Kalarchian, and J. Mccurley, "Do children lose and maintain weight easier than adults: a comparison of child and parent weight changes from six months to ten years," Obesity Research, vol. 3, no. 5, pp. 411-417, 1995.

[30] H. J. Khamis and A. F. Roche, "Predicting adult stature without using skeletal age: the Khamis-Roche method," $P e$ diatrics, vol. 94, no. 4, pp. 504-507, 1994.

[31] A. F. Roche, F. Tyleshevski, and E. Rogers, "Non-invasive measurements of physical maturity in children," Research Quarterly for Exercise and Sport, vol. 54, no. 4, pp. 364-371, 1983.

[32] R. M. Malina, “Top 10 research questions related to growth and maturation of relevance to physical activity, performance, and fitness," Research Quarterly for Exercise and Sport, vol. 85, no. 2, pp. 157-173, 2014.

[33] W. Abbott, S. Williams, G. Brickley, and N. J. Smeeton, "Effects of bio-banding upon physical and technical performance during soccer competition: a preliminary analysis," Sports, vol. 7, no. 8, p. 193, 2019.

[34] B. Bradley, D. Johnson, M. Hill et al., "Bio-banding in academy football: player's perceptions of a maturity matched tournament," Annals of Human Biology, vol. 46, no. 5, pp. 400-408, 2019.

[35] L. M. Bayer and N. Bayley, Growth Diagnosis: Selected Methods for Interpreting and Predicting Development from One Year to Maturity, University of Chicago Press, Chicago, IL, USA, 1959.

[36] S. P. Mitchell, M. Standage, F. B. Gillison, T. P. Dompier, and R. M. Malina, "Biological maturity status, body size, and exercise behaviour in british youth: a pilot study," Journal of Sports Sciences, vol. 27, no. 7, pp. 677-686, 2009.

[37] C. Drenowatz, O. Wartha, J. Klenk, S. Brandstetter, M. Wabitsch, and J. Steinacker, "Differences in health behavior, physical fitness, and cardiovascular risk in early, average, and late mature children," Pediatric Exercise Science, vol. 25, no. 1, pp. 69-83, 2013.

[38] F. Gillison, S. Cumming, M. Standage, C. Barnaby, and P. Katzmarzyk, "Assessing the impact of adjusting for maturity in weight status classification in a cross-sectional sample of UK children," BMJ Open, vol. 7, Article ID e015769, 2017.

[39] S. P. Cumming, C. Searle, J. K. Hemsley et al., "Biological maturation, relative age and self-regulation in male professional academy soccer players: a test of the underdog hypothesis," Psychology of Sport and Exercise, vol. 39, pp. 147-153, 2018.

[40] A. Trecroci, Z. Milanović, M. Frontini, F. M. Iaia, and G. Alberti, "Physical performance comparison between under 15 elite and sub-elite soccer players," Journal of Human Kinetics, vol. 61, no. 1, pp. 209-216, 2018.

[41] J. L. Oliver, C. A. Williams, and N. Armstrong, "Reliability of a field and laboratory test of repeated sprint ability," Pediatric Exercise Science, vol. 18, no. 3, pp. 339-350, 2006.
[42] M. Buchheit, A. Mendez-Villanueva, G. Delhomel, M. Brughelli, and S. Ahmaidi, "Improving repeated sprint ability in young elite soccer players: repeated shuttle sprints vs. explosive strength training," Journal of Strength and Conditioning Research, vol. 24, no. 10, pp. 2715-2722, 2010.

[43] A. Trecroci, S. Longo, E. Perri, F. M. Iaia, and G. Alberti, "Field-based physical performance of elite and sub-elite middle-adolescent soccer players," Research in Sports Medicine, vol. 27, no. 1, pp. 60-71, 2019.

[44] R. S. Lloyd, J. L. Oliver, M. G. Hughes, and C. A. Williams, "Reliability and validity of field-based measures of leg stiffness and reactive strength index in youths," Journal of Sports Sciences, vol. 27, no. 14, pp. 1565-1573, 2009.

[45] G. Markovic, D. Dizdar, I. Jukic, and M. Cardinale, "Reliability and factorial validity of squat and countermovement jump tests," Journal of Strength and Conditioning Research, vol. 18, no. 3, pp. 551-555, 2004.

[46] M. Hara, A. Shibayama, H. Arakawa, and S. Fukashiro, "Effect of arm swing direction on forward and backward jump performance," Journal of Biomechanics, vol. 41, no. 13, pp. 2806-2815, 2008.

[47] R. S. Lloyd, J. L. Oliver, M. G. Hughes, and C. A. Williams, "The influence of chronological age on periods of accelerated adaptation of stretch-shortening cycle performance in pre and postpubescent boys," Journal of Strength and Conditioning Research, vol. 25, no. 7, pp. 1889-1897, 2011.

[48] E. P. Flanagan and T. M. Comyns, "The use of contact time and the reactive strength index to optimize fast stretchshortening cycle training," Strength and Conditioning Journal, vol. 30, no. 5, pp. 32-38, 2008.

[49] M. M. Read and C. Cisar, "The influence of varied rest interval lengths on depth jump performance," Journal of Strength and Conditioning Research, vol. 15, no. 3, pp. 279-283, 2001.

[50] U. Granacher, O. Prieske, M. Majewski, D. Büsch, and T. Muehlbauer, "The role of instability with plyometric training in sub-elite adolescent soccer players," International Journal of Sports Medicine, vol. 36, no. 5, pp. 386-394, 2015.

[51] A. Votteler and O. Höner, "The relative age effect in the German football TID programme: biases in motor performance diagnostics and effects on single motor abilities and skills in groups of selected players," European Journal of Sport Science, vol. 14, no. 5, pp. 433-442, 2014.

[52] C. Zuber, M. Zibung, and A. Conzelmann, "Holistic patterns as an instrument for predicting the performance of promising young soccer players-a 3-years longitudinal study," Frontiers in Psychology, vol. 7, p. 1088, 2016.

[53] C. Carling, F. Le Gall, and R. M. Malina, "Body size, skeletal maturity, and functional characteristics of elite academy soccer players on entry between 1992 and 2003," Journal of Sports Sciences, vol. 30, no. 15, pp. 1683-1693, 2012.

[54] D. N. Deprez, J. Fransen, M. Lenoir, R. M. Philippaerts, and R. Vaeyens, "A retrospective study on anthropometrical, physical fitness, and motor coordination characteristics that influence dropout, contract status, and first-team playing time in high-level soccer players aged eight to eighteen years," Journal of Strength and Conditioning Research, vol. 29, no. 6, pp. 1692-1704, 2015.

[55] S Cobley, "Talent identification and development in youth sports," in Routledge Handbook of Youth Sport, K. Green and A. Smith, Eds., Routledge, Abingdon, UK, 2016.

[56] R. Philippaerts, R. Vaeyens, D. Cauwelier, J. Bourgois, and J. Vrijens, De Jeugdvoetballer Beter Begeleiden/Ghent Youth Soccer Project, Ghent University, Ghent, Belgium, 2004. 
[57] J. B. Vandendriessche, R. Vaeyens, B. Vandorpe, M. Lenoir, J. Lefevre, and R. M. Philippaerts, "Biological maturation, morphology, fitness, and motor coordination as part of a selection strategy in the search for international youth soccer players (age 15-16 years)," Journal of Sports Sciences, vol. 30, no. 15, pp. 1695-1703, 2012.

[58] R. Wormhoudt, G. J. Savelsbergh, J. W. Teunissen, and K. Davids, The Athletic Skills Model: Optimizing Talent Development through Movement Education, Routledge, London, UK, 2017. 